\title{
A SEXUALIDADE SILENCIADA NO AMBIENTE ESCOLAR E AS CONTRIBUIÇÕES DA SÉRIE SEX EDUCATION
}

\author{
SEXUALIDAD SILENCIADA EN EL ENTORNO ESCOLAR Y LAS \\ CONTRIBUCIONES DE LA SERIE SEX EDUCATION
}

\section{SEXUALITY SILENCED IN THE SCHOOL ENVIRONMENT AND THE CONTRIBUTIONS OF THE SERIES SEX EDUCATION}

\author{
Isabela MANCHINI ${ }^{1}$ \\ Jéssica da Costa JACINTO ${ }^{2}$ \\ Ricardo DESIDÉRIO ${ }^{3}$
}

RESUMO: A Educação Sexual é considera um tabu na sociedade. Os diálogos que deveriam, em suma, alicerçar informações e debates coerentes sobre sexualidade são transformados em um conjunto de achismos baseados em desinformações, revelando uma Educação Sexual informal perpassada por gerações e apoiada em dogmas morais e religiosos. A pesquisa tem como objetivo analisar a série Sex Education da Netflix e sua relevância para o debate da Educação Sexual. Trata-se de um estudo exploratório que nos permite refletir a escola como órgão inerente à sociedade, que se vê refletida em um paradigma marcado pelo reforço do senso comum atrelado às temáticas da sexualidade. Assim, denota-se que a escola deve ser responsável por disseminar uma Educação Sexual formal, baseada em estudos científicos acerca da sexualidade, mas esbarra em conceitos morais e deturpados de profissionais, impedindo, consequentemente, que haja uma discussão livre de dogmas e preconceitos e que, efetivamente, venha a sanar os questionamentos dos alunos da atual geração.

PALAVRAS-CHAVE: Educação. Sexualidade. Sociedade. Diálogo.

RESUMEN: La educación sexual se considera un tabú en la sociedad. Los diálogos que deberian, en definitiva, sustentar información coherente y debates sobre la sexualidad se transforman en un conjunto de desacuerdos basados en la desinformación, revelando una educación sexual informal que ha sido transmitida de generación en generación y sustentada en dogmas morales y religiosos. La investigación tiene como objetivo analizar la serie Sex

\footnotetext{
${ }^{1}$ Universidade Estadual Paulista (UNESP), Araraquara - SP - Brasil. Mestranda no Programa de Pós-graduação em Educação Sexual. Integrante do Grupo de Pesquisa em Educação e Diversidade - GPED/UNESPAR na linha Sexualidade e Educação Sexual. Colunista do site da rádio da cidade de Ibitinga-SP. ORCID: https://orcid.org/0000-0001-5039-5475. E-mail: isabela.manchini@unesp.br

${ }^{2}$ Universidade Estadual Paulista (UNESP), Araraquara - SP - Brasil. Mestranda Mestrando no Programa de Pósgraduação em Educação Sexual. Membro Grupo de Pesquisa em Educação e Diversidade (GPED/UNESPAR). Diretora voluntaria e fundadora da ONG Núbia Rafaela Nogueira. Bolsista FAPESP. ORCID: https://orcid.org/0000-0002-6192-0754. E-mail: costa.jacinto@unesp.br

${ }^{3}$ Universidade Estadual Paulista (UNESP), Araraquara - SP - Brasil. Docente no Programa de Pós-graduação em Educação Sexual, Pesquisador nos Grupos Sexualidade Vida/USP-CNPq, EDUSEX-Formação de Educadores e Educação Sexual (UDESC) e Grupo de pesquisa sobre educação e sexualidade- GEPEX (UNIOESTE). Doutorado em Educação Escolar (UNESP). ORCID: https://orcid.org/0000-0003-2779-2696. E-mail: contatodesiderio@hotmail.com
} 
Education de Netflix y su relevancia para el debate sobre educación sexual. Se trata de un estudio exploratorio que nos permite reflexionar sobre la escuela como órgano inherente a la sociedad, lo que se refleja en un paradigma marcado por el refuerzo del sentido común ligado a los temas de la sexualidad. Así, se advierte que la escuela debe ser la encargada de difundir una educación sexual formal, basada en estudios científicos sobre la sexualidad, pero cae sobre conceptos morales y tergiversados de los profesionales, impidiendo, en consecuencia, que exista una libre discusión de dogmas y prejuicios que, efectivamente, resolverá las interrogantes de los estudiantes de la generación actual.

PALABRAS CLAVE: Educación. Sexualidad. Sociedad. Diálogo.

ABSTRACT: Sex education is considered a taboo in society. The dialogues that should, in short, support coherent information and debates about sexuality are transformed into a set of disagreements based on misinformation, revealing an informal sexual education that has been passed down through generations and supported by moral and religious dogmas. The research aims to analyze Netflix's Sex Education series and its relevance to the Sex Education debate. It is an exploratory study that allows us to reflect on the school as an organ inherent to society, which is reflected in a paradigm marked by the reinforcement of common sense linked to the themes of sexuality. Thus, it is noted that the school should be responsible for disseminating a formal sexual education, based on scientific studies about sexuality, but it tumbles on moral and misrepresented concepts of professionals, preventing, consequently, that there is a free discussion of dogmas and prejudices that, effectively, will solve the questions of the students of the current generation.

KEYWORDS: Education. Sexuality. Society. Dialogue.

\section{Introdução}

Este artigo tem como objetivo salientar a relevância da inserção da Educação Sexual no currículo da escola através de uma abordagem emancipatória, a fim de causar reflexão sobre alguns pontos importantes que permeiam essa prática por meio de uma análise do seriado Sex Education, disponível na Netflix, e mostrar a relevância da série nesse período em que enfrentamos vários retrocessos referentes à sexualidade dentro da escola, na família e na sociedade.

Os estudos para embasamento foram feitos através de artigos presentes na Revista Ibero-Americana de Estudos em Educação, disponibilizados pelos organizadores desse dossiê, além de outros autores. No entanto, nos atentamos à uma parte referente à Metodologia para esclarecer qual caminho trilhamos para chegar ao resultado desse trabalho.

Optamos pelo estudo do seriado por compreender que este possui enfoque na temática da sexualidade de uma forma bem atual: como ela é vista pelos professores e diretor, o despreparo que ambos enfrentam, o excesso de curiosidades dos alunos e a imprescindibilidade 
de um profissional capacitado para lidar a temática com propriedade e entendimento. Pontos estes que apresentam questionamentos e reflexões no decorrer desse artigo.

Queremos propor uma reflexão acerca dos tabus que a Educação Sexual enfrenta, assim como os retrocessos e, consequentemente, a importância da quebra desse olhar promíscuo e errôneo para o tema, e que, dessa forma, os professores assumam uma prática libertadora e de transformação social ao tratar da sexualidade dentro das escolas.

Desejamos ainda pensar, estudar e informar sobre a importância e necessidade dessa disciplina para a formação global dos educandos para, assim, também diminuir alguns problemas que enfrentamos na sociedade hoje em dia, como violência sexual, gravidez precoce, machismo, racismo, entre outros que foram e ainda serão citados ao longo deste trabalho. É evidente a urgência de tal assunto ser cada vez mais ser levado para além dos espaços físicos da escola de forma sistematizada.

Dessa forma, consideramos que o seriado Sex Education demonstra de forma nítida e questionadora pontos importantes a serem debatidos dentro da escola e pela sociedade.

Este artigo e resultado de uma pesquisa de caráter exploratório, tendo em vista que o objetivo desse método é fornecer informações necessárias para ampliar o conhecimento, isso se dá pelo caráter maleável proporcionado pelo melhor desenvolvimento do método. O método exploratório permite ao pesquisador ter noção ampla de novos temas a serem investigados além de demonstrar a relevância do tema e a sua contribuição para a academia e sua pertinência no âmbito das experiências humanas.

Geralmente proporcionam maior familiaridade com o problema, ou seja, têm intuito de torná-lo mais explícito. Seu principal objetivo é o aprimoramento de ideias ou a descoberta de intuições. Embora o planejamento da pesquisa exploratória seja bastante flexível, na maioria dos casos pode assumir a forma de pesquisa bibliográfica ou estudo de caso (HANDEM; MATIOLI; PEREIRA; NASCIMENTO, 2007, p. 91).

Sendo assim, para a elaboração dessa escrita, partimos de um planejamento detalhado e atencioso na seleção dos materiais para serem lidos e interpretados, grande parte dos artigos selecionados são artigos disponíveis na Revista Ibero Americana, além de bibliografias de autores que dialogam sobre a necessidade de se difundir conhecimentos científicos sérios sobre o tema da Educação Sexual, isso aliado à análise do seriado Sex Education. Levamos em consideração a contribuição que sons, imagens e movimentos contribuem para o entendimento de diversos temas facilitando a compreensão (DESIDÉRIO, 2015), especialmente quando trata se de assuntos interpretados de forma tão distorcida na nossa sociedade, como a Educação Sexual dentro do contexto escolar. 


\section{Desenvolvimento}

A sexualidade se configura como um dos temas mais polêmicos da atualidade, tendo em vista que ela ultrapassa as barreiras do sexo compreendido como unicamente para fins de reprodução, abarcando em seu processo de construção subjetiva o desenvolvimento biológico, psíquico e sociocultural, além de ser um território da descoberta do prazer. Sexualidade é um traço inerente ao ser humano estando presente desde o nascimento, perpassando todas as demais fases da vida e, sendo assim, desenha-se uma estratégia de saber e poder.

[...] Ela é o nome que pode ser dado a um construto histórico: não há uma realidade furtiva que é difícil de apreender, mas uma enorme superfície em forma de rede na qual as estimulações dos corpos, a intensificação dos prazeres, o incitamento ao discurso, a formação de um conhecimento especializado, o reforço dos controles e resistências estão vinculados uns aos outros, de acordo com algumas poucas estratégias importantes de saber e poder (BRITZMAN, 2003, p. 100-101).

Em face do exposto, revela-se urgente um olhar epistêmico para o tema. A visão do corpo hoje vigente é condicionada pela sociedade capitalista, mercantil e midiática, conduzindo as dimensões limitadas e reducionistas do corpo, desumanizando as relações sociais e afetivosexuais (BONFIM, 2012, p. 61).

Diante disso, torna-se imprescindível investigar as possibilidades de desconstrução e reconstrução de novas formas de pensar a experiência humana. Muito se especula sobre qual deveria ser o ambiente adequado para se trabalhar essa temática com as informações coerentes e necessárias para atender as expectativas das novas gerações. No início de 2019, a conhecida plataforma streaming Netflix, que atualmente possui mais de 160 mil assinantes, lançou a primeira temporada da série intitulada Sex Education dedicada ao público jovem. Com enfoque na temática da sexualidade, a série alcançou resultados inesperados, sucesso de audiência e popularidade entre os seriados disponibilizados na plataforma digital.

Criada pela roteirista Laurie Nunn, Sex Education foi inspirada em filmes de John Hughes, um famoso diretor americano que deixou em seu legado uma diversa gama de filmes das mais diversas temáticas, entretanto, a maioria de seus filmes se dedicava à temáticas adolescentes com conotações sexuais bem próximas da experiência e dos anseios típicos dessa fase tão peculiar do desenvolvimento humano.

A $1^{\mathrm{o}}$ temporada da série britânica, original da Netflix, apresenta um toque de humor ácido e cenas muito realistas de temáticas consideradas tabus como sexo, masturbação, nudismo, relações homoafetivas, autoestima, fantasias, descoberta da personalidade, aborto, relações familiares, saúde e prazer da mulher. Embora os personagens sejam clichês do típico 
formato de filmes para adolescentes no colegial, o desenvolvimento das personagens se esculpe de forma diferenciada, começando por serem interpretadas por um elenco jovem pouco conhecido.

O enredo da história se passa no colégio Moordale, onde o virgem Otis (Asa Butterfiel) e sua companheira, a típica adolescente problemática Maeve Wiley (Emma Mackey), criam uma clínica para dar conselhos sexuais e afetivos aos membros da escola, a partir dos próprios questionamentos dos colegas em relação à forma como vivenciam a própria sexualidade.

A facilidade do personagem Otis em lidar com assuntos relacionados à sexualidade se dá pela sua formação familiar, visto que sua mãe Jean, vivida por Gillian Anderson, tem como formação e profissão a função de terapeuta sexual e escritora de livros da mesma temática, assim como seu pai Remy (James Purefoy), embora ausente, também é um escritor da temática da sexualidade, ainda que se dedique à temática da masculinidade nos padrões tipicamente heteronormativos. O percurso da primeira temporada se desenrola em uma costura que culmina em uma teia sexual de vários personagens complexos e seus desdobramentos. Vale citar, por exemplo, o personagem Eric (Ncuti Gatwa), melhor amigo gay do personagem principal Otis, que se destacou pela construção do personagem durante a trama, dando visibilidade às questões raciais, à homofobia internalizada no ambiente escolar, ao amadurecimento e à aceitação da homossexualidade no contexto familiar. O personagem Eric é essencial para compor a série, a partir do personagem e seu desenrolar são propostas problematizações que, geralmente, não se encontram nos contextos de outras séries dedicadas ao público adolescente e jovem. A primeira temporada optou por trabalhar assuntos como aborto na adolescência, masculinidades e comportamentos tóxicos, masturbação e prazer feminino.

No início de 2020, foi lançada a segunda temporada da série que fez jus ao sucesso da primeira temporada, chegando estar no topo dos assuntos mais comentados do Twitter no Brasil pela sua importância no contexto de formação humana e sexual dos usuários da plataforma online Netflix.

A $2^{\circ}$ temporada de Sex Education trouxe para a tela dos smartphones e computadores questões complexas relacionadas à informação e à desinformação sobre sexualidade, quem deveria ter o domínio para lidar com as especulações e os anseios dos adolescentes que clamam por respostas aos seus dilemas sexuais e afetivos.

A história da clínica sexual de conselhos para adolescentes de Otis e Maeve é apenas um cenário para questões mais profundas desenvolvidas na trama, como o período da adolescência e maneira como se desenvolve a maturidade. 
O colégio Moordale na trama não estava preparado para lidar com a dúvidas e necessidades de seus alunos referentes a sexualidade, então, nesse momento da trama, é explicitada a crítica aos sistemas escolares de ensino e suas visões puramente biologicistas da educação sexual. A série, nesse ponto, acaba por fixar como ponto central da temporada a ausência de diálogo entre adolescentes e escola e o reflexo disso na formação humana dos discentes.

Há muitos embates entre a família e as instituições de ensino sobre quem deveria ser responsável por informar os alunos, isto porque “[...] envolve preconceitos arraigados em uma moral sexual patriarcal [...]" (BONFIM, 2012, p. 65). Notamos que os professores argumentam não se sentirem preparados para discutir o tema, isso se deve a inexperiência e a ausência de conhecimentos científicos sobre a sexualidade humana, tendo em vista a ausência de cursos de formação, além de eles possuírem valores e tabus arraigados de seu processo de construção enquanto sujeito na sociedade atual. Nessa perspectiva, a visão que prevalece é “[...] aquela que cada família recebeu de seus antepassados e passou para seus filhos, quase sempre repressiva, dogmática, pecaminosa e vergonhosa" (BONFIM, 2012, p. 65).

Diante do exposto, assume-se o princípio de que possibilitar que a escola discuta a sexualidade em seu caráter multidimensional, implica também que a formação do professor contemple esse aspecto. Isto porque esta discussão depende, dentre outros fatores, de docentes que se sintam capazes de abordar e problematizar não apenas aspectos associados ao corpo biológico, a saber: DSTs, anatomia e fisiologia do sistema reprodutor masculino e feminino, mas, sobretudo aspectos sociais, culturais, éticos, filosóficos, entre outros, pois são estes aspectos que, em conjunto com a biologia, darão sentido à sexualidade $\mathrm{e}$ auxiliarão os professores a desenvolverem esta temática em sala de aula junto aos estudantes, na busca por possibilitar a estes atores sociais uma vivência responsável de sua sexualidade. Portanto, entende-se que o professor é o ator/ autor social a quem cabe o papel de, na escola, auxiliar o estudante a subjetivar (ZOCCA; MUZZETI; NOGUEIRA; RIBEIRO, 2015, p. 1449).

Ao observar o avanço de estratégias anti-Educação Sexual no âmbito político, com apoio popular de famílias que se organizam em sociedade civil baseada no conservadorismo e no puritanismo, pressupõe-se que a melhor forma de trabalhar a sexualidade vista pela sociedade é silenciando toda e qualquer forma de intervenção acerca de informações referentes ao tema.

Pais e educadores devem entender que ocultar o assunto também significa posicionar-se sobre ele. A neutralidade pode ser pior que uma posição contrária: a cultura do silêncio que ainda impera na escola e na família esquece que não precisamos necessariamente utilizar o diálogo para expressar nossos posicionamentos. A omissão, os gestos, as proibições carregadas de valores 
moralistas e socioculturais são uma maneira de contribuir para que o preconceito e os tabus sexuais se perpetuem (BONFIM, 2012, p. 64).

Esse tipo de visão constrói uma imagem de que Educação Sexual nas escolas é uma prática imoral e promíscua e que esta seria responsável por induzir crianças precocemente a ter relações sexuais. Interpretações assim ainda recomendam a abstinência como prevenção de gravidez e de doenças sexuais. Em meados de 2004, surge um movimento político no Brasil denominado Escola Sem Partido, criado pelo advogado Miguel Nagib que, na época, atuava no cargo de procurador do Estado de São Paulo. O movimento surgiu depois de supostas alegações de doutrinações político-partidárias em escolas para fins ideológicos, o argumento utilizado era de que professores trabalhavam com um conceito que se intitulou Ideologia de Gênero. Para compreender o cenário desta afirmação, primeiro é preciso se apropriar do conceito de gênero.

Gênero é uma categoria teórica criada na segunda metade do século XX para designar as construções sociais sobre o feminino e o masculino [...] Não é algo que nasce com a pessoa, não é algo determinado pela biologia [...] não dá para dizer que as mulheres são todas iguais ou que os homens são todos iguais, pois nos deparamos com uma enorme diversidade de significados, formas de ser e estar no mundo e na sociedade e, inclusive, diferentes formas de lidar e sentir a sexualidade [...] os significados de gênero presentes em nossa sociedade são pautados em relações de poder [...]. Essa ideia baseia-se, geralmente, no determinismo biológico, e na construção das diferenças de forma hierarquizada e gera desigualdades e opressões. E é nesse ponto que os grupos conservadores se apoiam para criticar a construção da igualdade de gênero, porque trazer à tona a discussão de gênero significa mostrar que existem diferenças significativas entre as mulheres, entre os homens, que existem diferentes masculinidades e feminilidades, diferentes formas de expressar a afetividade, a sexualidade, as características de gênero, denunciam o desrespeito à diversidade e pregam a igualdade e o respeito à dignidade humana e as diferenças. Portanto, não dá para falar em ideologia de gênero porque gênero não é uma ideologia. Muito pelo contrário, trazer a discussão de gênero é uma forma de desconstruir uma ideologia baseada na natureza e na biologia, desconstruir a desigualdade entre homens e mulheres em nossa sociedade e, inclusive, desconstruir as desigualdades entre os grupos de mulheres entre si e entre os grupos de homens (TALLES, 2016, p. 2).

Posto isto, compreendemos que houve uma deturpação na compreensão do conceito de Gênero, o que fez crescer um panorama de medo dos docentes nas escolas para abordar o tema da sexualidade.

Criou-se uma falácia apelidada de ideologia de gênero, que induziria a destruição da família tradicional, à legalização da pedofilia, ao fim da ordem natural e das relações entre os gêneros e que nega a discriminação e violência contra as mulheres e pessoas LGBT comprovadas com dados oficiais e estudos científicos. Utilizou-se de desonestidade intelectual, formulando argumentos sem fundamentos científicos e replicando-os nas mídias sociais para serem engolidos e regurgitados pelos fiéis acríticos que os aceitam como 
verdades inquestionáveis. Utilizou-se também como uma espécie de terrorismo moral, atribuindo o status de demônio às pessoas favoráveis ao respeito à igualdade de gênero e diversidade sexual na educação, além de intimidar profissionais de educação com notificações extrajudiciais, com ameaça de processo contra quem ousasse abordar esses assuntos na sala de aula. Criou-se um movimento para apagar o assunto gênero do currículo escolar (REIS; EGGERT, 2017, p. 20).

Dentro desse ponto de vista, abdica - se de uma das principais características humanas, a sexualidade, tão fundamental para um bom desenvolvimento humano. Essa circunstância faz surgir o medo por parte do professor em abordar o tema e sofrer retaliações. Sendo assim, podemos dizer que recebemos mais Educação Sexual de maneira informal que formal (sistematizada no ambiente escolar) durante a nossa vida.

[...] para melhorar esse quadro, primeiramente se faz necessária uma reeducação sexual de todos nós. Não se faz educação sexual de maneira dogmática ou doutrinária. Não se deve sustentar um projeto de educação sexual sobre o voluntariado expontaneísta, mesmo aquele carregado de boas intenções e altruísmo. A vontade deve ser o motor das práticas transformadoras, mas estas somente se completam com consciência crítica que deve ser sistematicamente buscada pela ciência e pelo trabalho intelectual de pesquisa e aprofundamento [...] (BONFIM, 2012, p. 65).

Falar sobre Educação Sexual na escola ainda se mostra um assunto complexo, especialmente quando este assunto permeia o espaço escolar frequentado por uma diversidade ampla de adolescentes. Porém, devemos ressaltar que, durante toda a nossa formação, aprendemos sobre Educação Sexual de modos oportunos, com um amigo quando surge alguma dúvida, com as reações dos nossos pais quando queremos saber sobre algo relacionado, e também dentro da escola, na forma como o professor aborda o tema no contexto escolar, a escola se posiciona para educar seus alunos para a sexualidade.

[...] a questão sexual não pode ser desvinculada da transformação social, que precisa ser percebida como processo, em uma perspectiva dialética, ou seja, em um contexto em que verdades, ideias, visões de mundo, experiências e vivências não são absolutas. Assim, a proposta de Educação Sexual é toda ação que envolve a aprendizagem sobre sexualidade humana, que esteja inserida em contexto histórico-cultural e que permita a busca por sentimentos, valores, emoções e atitudes frente à vida sexual (DESIDÉRIO, 2014, p. 88).

Encontramos nos documentos e leis educacionais os suportes necessários para alicerçar abordagem da Educação Sexual na escola. Destaca-se a Lei de Diretrizes e Bases da Educação Nacional no 9.934, de 20 de dezembro de 1996 (LDBEN 9394\96), com destaque para o Art. 2 que salienta que "A educação, dever da família e do Estado, inspirada nos princípios da liberdade e nos ideais de solidariedade humana, tem por finalidade o pleno 
desenvolvimento do educando [...]", ainda complementa o Art. 3, quando o parágrafo I garante legalmente “[...] igualdade de condições para o acesso e permanência na escola [...]”. Seguindo o mesmo trajeto, podemos citar a Constituição da República Federativa do Brasil de 1988 (CF 88), que no Art. 205 corrobora ao dizer ser “A educação, direito de todos [...] visando ao pleno desenvolvimento da pessoa, seu preparo para o exercício da cidadania [...]" (BRASIL, 1996, Art. 205).

Segundo documentos legais, devemos promover uma educação para a sexualidade junto com professores e alunos. É importante salientar que os PCN (Parâmetros Curriculares Nacionais) desde 1996 trazem a discussão da Orientação Sexual para dentro do espaço escolar através de temas transversais. Apesar de problemáticas indicadas por diversos pesquisadores como, por exemplo, o tratamento da sexualidade a partir de uma perspectiva biológica e a abordagem superficial das questões de gênero, o documento oficial corresponde à legitimação da abordagem da diversidade sexual e de gênero na escola (SILVA; BRANCALEONI; OLIVEIRA, 2019).

Nos Temas Transversais demonstrados nos PCN encontramos os alicerces necessários para fundamentar o ensino da Educação Sexual nas escolas. Existem seis competências para a formação do aluno, segundo o caderno de Temas Transversais, são eles: ética; orientação sexual; meio ambiente; saúde; pluralidade cultural e trabalho e consumo. Isto é, a orientação sexual é relevante para a compressão humana.

A abordagem do corpo como matriz da sexualidade tem como objetivo propiciar aos alunos conhecimento e respeito ao próprio corpo e noções sobre os cuidados que necessitam dos serviços de saúde. A discussão sobre gênero propicia o questionamento de papéis rigidamente estabelecidos a homens e mulheres na sociedade, a valorização de cada um e a flexibilização desses papéis. O trabalho de prevenção às doenças sexualmente transmissíveis/AIDS possibilita oferecer informações científicas e atualizadas sobre as formas de prevenção das doenças. Deve também combater a discriminação que atinge portadores do HIV e doentes de AIDS de forma a contribuir para a adoção de condutas preventivas por parte dos jovens (BRASIL, 1997, p. 34).

Por apreendermos a importância da sexualidade para a formação humana defendemos que a Educação Sexual deve ser trabalhada desde a educação infantil. Aqui atentaremos para sua relevância durante o período da adolescência, uma vez que é neste contexto cheio de mudanças para o adolescente que surgem muitas preocupações, entre elas, a gravidez indesejada, as doenças sexualmente transmissíveis, o uso adequado de preservativos, conhecimentos sobre o corpo, a iniciação das relações sexuais imaturamente, a masturbação, o uso de contraceptivos, etc. 
Por isso a Educação Sexual é indispensável, principalmente neste momento da vida quando as transformações e novidades são vivenciadas ao lado das dúvidas e incertezas (ZOCCA; MUZZETI; NOGUEIRA; RIBEIRO, 2016). Conceituando a abordagem a qual advogamos que, segundo Figueiró (1996), refere-se a uma abordagem política porque é voltada para a emancipação do indivíduo, desenvolvendo criticidade nos apontamentos sociais, políticos e culturais acerca de sua sexualidade da forma mais ampla (gênero, identidade, orientação, desejo, prazer, valores) não só de si próprio, mas também de todo meio em que se encontra, temos que:

A Orientação Sexual na escola deve ser entendida como um processo de intervenção pedagógica que tem como objetivo transmitir informações e problematizar questões relacionadas à sexualidade, incluindo posturas, crenças, tabus e valores a ela associados. Tal intervenção ocorre em âmbito coletivo, diferenciando-se de um trabalho individual, de cunho psicoterapêutico e enfocando as dimensões sociológica, psicológica e fisiológica da sexualidade. Diferencia-se também da educação realizada pela família, pois possibilita a discussão de diferentes pontos de vista associados à sexualidade, sem a imposição de determinados valores sobre outros. O trabalho de Orientação Sexual visa propiciar aos jovens a possibilidade do exercício de sua sexualidade de forma responsável e prazerosa. Seu desenvolvimento deve oferecer critérios para o discernimento de comportamentos ligados à sexualidade que demandam privacidade $\mathrm{e}$ intimidade, assim como reconhecimento das manifestações de sexualidade passíveis de serem expressas na escola (FIGUEIRO, 1996, p. 34).

A consequência desse posicionamento da escola e professores perante tal tema faz com que alunos busquem informações em inúmeras fontes de comunicação, e essas informações adquiridas chegam deturpadas, são incoerentes, deseducam ao invés de educarem. Vivemos um momento em que já é visível que mudanças nesse sentido são necessárias, pois há tempos que a Educação Sexual, infelizmente, tem permanecido apenas nos documentos legais e tem sido barrada nos portões da escola, causando consequências ostensivas em nossa sociedade.

A série Sex Education é toda ambientada para proporcionar intervenções que possibilitem ao telespectador desconstruir conhecimentos pré-concebidos, e ainda, dá um retorno rico em conhecimento científico. O seriado é formatado para se pensar e avaliar a complexidade das relações humanas e a diversidade afetiva na contemporaneidade.

[...] a escola é uma das instituições de ensino cujo papel é a socialização dos conhecimentos sistematizados. A escola necessita ser voltada para fora de si, para o atendimento das necessidades de toda a sociedade viabilizando os conflitos existentes, atendendo aos interesses de uma sociedade de classes (BIANCON, 2016, p. 25). 
Logo, observamos que a temática é obrigatória e assegurada por documentos oficiais importantes para compor o currículo educacional, para além do currículo os alunos possuem necessidades, curiosidades típicas oriundas dessa fase maturação e se sentem dispostos para debater o assunto dentro da escola, bem como no ambiente familiar.

\section{Considerações finais}

Apesar das críticas e entraves citados anteriormente, a escola é considerada o ambiente propício para se trabalhar a temática da sexualidade pela aproximação e pelo acesso aos alunos em idade escolar, como abordado no decorrer do artigo, mostra-se notória a curiosidade dos adolescentes em conversar sobre o tema e também a fragilidade da escola em trabalhar essa questão, reflexo de uma sociedade que optou por uma Educação Sexual baseada em conceitos morais e religiosos que culminaram em décadas de atraso e desinformação, o que acaba gerando diversas condições de violência como o machismo, a misoginia, a homofobia, a violência doméstica, a violência de gênero, o abuso sexual infantil, entre outras formas de violência que refletem a falta de formação humana no âmbito da sexualidade.

Portanto, é urgente que a escola se encarregue de produzir esse diálogo de maneira a atender as expectativas do alunado dessa geração, e das futuras que ingressarão no ambiente escolar. É significativo reforçar que os PCN que já oferecem uma base legal para que esse debate ocorra.

Por fim, há de se concluir a importância da série Sex Education no atual contexto histórico marcado por tantos retrocessos. Este é um conteúdo acessível que discute sexualidade livre de tabus e, por essa razão, é benéfico para a sociedade em geral, visto que a partir de conteúdos abordados no enredo da série, muitos adolescentes e até adultos relataram terem refletido sobre conteúdos que jamais haviam sido lhes apresentados ou questionados, detalhes tão simples e estigmatizados ao mesmo tempo.

Na mesma perspectiva, o seriado demonstra a seriedade e a dimensão da formação necessária para que o profisssional seja capacitado para lidar com a disseminação dos conteúdos referentes à sexualidade para que a mesma seja embasada de forma científica, didática e natural, de forma a não produzir inverdades e incoerências baseadas em conhecimentos rasos e deturpados. Ademais, existe a preocupação de que o tema seja trabalhado com espontaneidade e que seu alcance seja entendível aos educandos da atualidade e das futuras gerações, ressaltando que educar sexualmente adolescentes e jovens é vantajoso e proveitoso para toda a sociedade. 


\section{REFERÊNCIAS}

BIANCON, M. L. Educação em sexualidade crítica: formação continuada de professoras (es) com fundamentos na pedagogia histórico-crítica. Orientadora: Ana Lúcia Olivo Rosas Moreira. 2016. 186 f. Tese (Doutorado) - Universidade Estadual de Maringá, Maringá, 2016.

BONFIM, C. Educação sexual a formação de professores: da educação sexual que temos à educação sexual que queremos. João Pessoa: Editora Universitária da UFPB, 2010.

BONFIM, C. Desnudando a educação sexual. Campinas: Papirus, 2012.

BRASIL. Lei n. 9.394, de 20 de dezembro de 1996. Lei de Diretrizes e Bases da Educação Nacional. Diário Oficial da União: Seção 1, Brasília, DF, n. 248, p. 27833, 23 dez. 1996.

BRASIL. Ministério de Educação Fundamental. Parâmetros Curriculares Nacionais: pluralidade cultural, orientação sexual. Brasília: MCE/SEF, 1997.

BRITZMAN, D. O que é essa coisa chamada amor: identidade homossexual, educação e currículo. Educação e Realidade, Porto Alegre, v. 21, n. 1, jan./jul. 2003.

DESIDÉRIO, R. Educação sexual e o direito da criança e do adolescente: Por que e para que ensinar a temática na escola? Capítulo 4? In: MAIA, J. S. S.; BIANCON, M. L. (Org.).

Educação das relações de gênero e em sexualidades: reflexões contemporâneas. Curitiba: Appris, 2014.

FIGUEIREDO, N. M. A. A produção teórica no brasil sobre educação sexual. Caderno de pesquisa. São Paulo, agosto 1996. Disponível em:

http://publicacoes.fcc.org.br/ojs/index.php/cp/article/view/795. Acesso em: 05 abril 2020.

FIGUEIREDO, N. M. A. Método e metodologia na pesquisa científica. 2. ed. São Caetano do Sul, 2007. p. 89-106.

KUNZ, E. Pedagogia crítico-emancipatória. In: GONZÁLES, J.; FENSTERSEIFER, P. E. (Org.). Dicionário crítico de educação física. Ijuí: Ed Unijuí, 2005. p. 316-318.

RANCISCATI, C. S. S.; LEIVAR, A. P. B.; RODRIGUES, R. O. Base nacional comum curricular e diversidade sexual e de gênero: (des)caracterizações. Revista Ibero-Americana de Estudos em Educação, Araraquara, p. 1538-1555, junho, 2019. ISSN 1982-5587. DOI: https://doi.org/10.21723/riaee.v14iesp.2.12051

REIS, T.; EGGERT, E. Ideologia de Gênero: Uma falácia construída sobre os planos de educação brasileiros. Educação \& sociedade, Campinas, v.38, n.138, p. 9-26, jan./mar., 2017. DOI: https://doi.org/10.1590/es0101-73302017165522

SILVA, R. D. Educação audiovisual da sexualidade: olhares a partir do Kit AntiHomofobia. 2015. 144 f. Tese (Doutorado) - Universidade Estadual Paulista, Araraquara, 2015. Disponível em: http://hdl.handle.net/11449/126523. Acesso em: 3 mar. 2020.

TELLES, E. O. Igualdade de gênero x ideologia de gênero. INEQ. 2016. Disponível em: http://ineq.com.br/igualdade-de-genero-x-ideologia-de-genero/. Acesso em: 15 fev. 2020. 
ZOCCA, A. R.; MUZZETI, L. R.; NOGUEIRA, N. S.; RIBEIRO, P. R. M. Percepções de adolescentes sobre sexualidade e educação sexual. Revista Ibero-Americana de Estudos em Educação, Araraquara, p. 1463-1476, jan. 2016. ISSN 1982-5587. DOI:

https://doi.org/10.21723/riaee.v10i6.8331

\section{Como referenciar este artigo}

MANCHINE, I.; JACINTO, J. C.; DESIDÉRIO, R. A sexualidade silenciada no ambiente escolar e as contribuições da série Sex Education. Revista on line de Política e Gestão Educacional, Araraquara, v. 24, n. esp. 3, p. 1780-1792, nov. 2020. e-ISSN:1519-9029. DOI: https://doi.org/10.22633/rpge.v24iesp3.14276

Submetido em: 10/01/2020

Revisões requeridas: $20 / 07 / 2020$

Aprovado em: 30/10/2020

Publicado em: 30/11/2020 